https://doi.org/10.30910/turkjans.595216

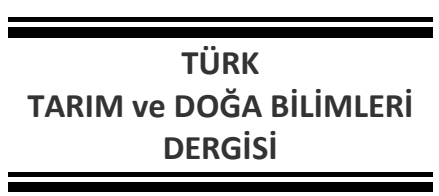

TÜRK

DERGISI

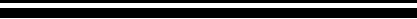

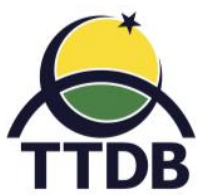

www.dergipark.gov.tr/turkjans

Araştırma Makalesi

\title{
Erzurum İli Süt Sığırcılığı İşletmelerinin Yenilikleri Benimseme Açısından Değerlendirilmesi
}

\author{
Sinan KILIÇTEK ${ }^{1}$, Adem AKSOY*
}

${ }^{1}$ T.C. Sanayi ve Teknoloji Bakanlığı DAP Bölge Kalkınma İdaresi Başkanlığı, Erzurum

${ }^{2}$ Atatürk Üniversitesi Ziraat Fakültesi Tarım Ekonomisi Bölümü, Erzurum

*Sorumlu yazar: aaksoy@atauni.edu.tr

Geliş Tarihi: 06.03.2019

Düzeltme Geliş Tarihi: 09.06.2019

Kabul Tarihi: 26.06.2019

Özet

Türkiye'de son yıllarda modern üretim yapan işletme sayısında önemli artışlar yaşansa da serbet piyasa koşullarında rekabet edebilecek işletme sayısı oldukça azdır. Özellikle çalışma alanında önemli bir hayvancılık kültürü olmasına rağmen bölgedeki süt sı̆̆ırcılığı işletmelerinde yenilikler yeterince benimsenmemiş olup üretim hala geleneksel yöntemlerle yapıımaktadır. Çalışma materyalini, Erzurum ilinde süt sığırcılı̆̆ı faaliyetini sürdüren 103 adet anket oluşturmaktadır. Erzurum ilinde faaliyet gösteren süt sığırcılığı işletmelerinde üreticiler tarafından benimsenen süt sağım ünitesi, süt soğutma tankı, gübre sıyırıcı, otomatik suluk, kaşıyıcı, buzağı ünitesi, karantina alanı, doğumhane, yem deposu, suni tohumlama, havalandırma, teknik destek, silaj kullanımı şeklinde 13 adet yenilik ele alınmıştır. İşletmenin kullandığı yeniliklerin benimsemesinde etkili olan faktörlerin tespitinde Sıralı Probit Modeli kullanıımıştır. Çalışmanın bağımlı değişkeni yeniliklerin benimsenme düzeyi düşük, orta ve yüksek şeklinde 3 gruba ayrılmıştır. Model sonucuna göre; ailedeki birey sayısı, tarımsal amaçlı kredi kullanım durumu, yıllık tarım dışı gelir, sosyal güvenlik, yeni teknolojileri uygulamanın gelirde değişim meydana getirmesi, yeniliğin ucuz olması, yenilikle ilgili bilgi sahibi olmak, yeniliğin denenebilir olması, yeniliği diğer çiftçilerin uyguluyor olması, sütün pazarlama durumu, sütün pazarlama şekli, sütün pazarlama süresi ve büyükbaş hayvan sayısı değişkenleri istatistiksel açıdan önemli bulunmuştur.

Anahtar kelimeler: Yenilik, süt sığırcılığı, sıralı probit modeli, Erzurum.

\section{Evaluation with Regards to Adoption of Innovations of Diary Milk Business Managements in Erzurum Province}

\footnotetext{
Abstract

While there have been significant increases in the number of modern production businesses in recent years the number of holdings to compete in free market conditions is quite low. Although there is an important livestock culture in the study area, innovations in dairy cattle farms in the region have not been sufficiently adopted and the production is still carried out by traditional methods. The study material consists of 103 questionnaires which are active in dairy cattle in the province of Erzurum. Adopted by producers in dairy cattle enterprises operators in Erzurum province addressed 13 innovations such as milk milking unit, milk cooling tank, manure scraper, automatic drinker, trainer, calf unit, quarantine area, delivery room, feed store, artificial insemination, ventilation, technical support, silage use in dairy cattle farms. Ordered Probit Model was used to determine the factors that effect the adoption of innovations. The dependent variable of the study was divided into three groups: low, medium and high. According to the model result; the number of individuals in the family, the use of loans for agricultural purposes, the annual non-agricultural income, social security, the introduction of new technologies to bring about changes in income, the innovation to be cheap, to have information about innovation, to be innovative, to be tried innovation,
} 
to be applied by other farmers, milk marketing status, marketing, milk marketing period and number of bovine animals were found to be statistically significant.

Key words: Innovation, dairy cattle, ordered probit model, Erzurum.

\section{Giriş}

Dünya nüfusunun sürekli arttığı günümüzde kaliteli ve dengeli beslenme ülkelerin gündeminde önemli bir yer tutmaktadır. Özellikle son yıllarda etkisini daha çok hissettiğimiz küresel ısınma ile birlikte tarımsal üretimdeki istikrarsızlık ve bilinçlenmenin artması beslenmeye verilen önemi artırmıştır. Günümüz dünyasında insanoğlunun beslenebilmesi ancak tarım sektörünün etkin ve sürdürülebilir şekilde yürütülmesiyle mümkün olacaktır.

Beslenme konusunda dünya genelinde yaşanan bu durum, Türkiye'de de etkisini giderek hissettirmeye başlamıştır. Toplam nüfusu 80810525 ve 38002 bin hektar tarım ve 14617 bin hektar çayır ve mera arazisine sahip olan Türkiye tarım sektöründe önemli bir potansiyele sahiptir (Anonim, 2019). Doğu Anadolu bölgesi dikkate alındığında 2489869 hektarlık işlenen tarım arazi varlığı ile Türkiye toplam işlenen tarım arazisi varlığının \%10.4'ünü oluşturmaktadır. Özellikle bölgenin doğal ve bölgede olmayan geniş çayır-mera varlığı hayvansal üretim için ideal şartların olduğunu göstermektedir (Kara ve Kızıloğlu 2014).

Büyükbaş hayvan varlığı dikkate alındığında Erzurum ili Türkiye büyükbaş hayvan varlığının \%4.5'lik kısmına sahiptir. 731282 baş hayvan varlığı ile Erzurum ili TRA bölge hayvan varlığının \%33.5'ine sahip olup Türkiye'de Konya ilinden sonra ikinci sırada yer almaktadır. Toplam süt üretimi bakımından ise 860625 ton/yıl ile Konya ve İzmir, illerinden sonra üçüncü sırada bulunmaktadır (Anonim, 2019).

Hayvancılık, topoğrafik özellikleri nedeniyle toprak işlemeye elverişsiz olan bölgelerde önemli bir geçim kaynağıdır. Ancak bu tür hayvancılık çoğunlukla geleneksel tekniklerle yürütülmekte ve gelişmekte olan ülkelerde yapılan hayvancılıkla kıyaslandığında oldukça geri kalmaktadır (Akbay ve Boz 2005). Bu nedenle süt sığırcılığı sektöründe rekabetin yoğun yaşandığı günümüzde ayakta kalmanın tek yolu işletmelerde, sektörde yaşanan yeniliklerin uygulanması ile gerçekleştirilebilecektir. Tarımsal yeniliklerin benimsenmesi ve yayılması tarımı ve dolayısıyla kırsal kesimde yaşayan toplumun gelişimi açısından son derece önemlidir. İşletmelerde üretim maliyetlerini düşürmenin bir yolu da maliyetler üzerinde etkili olan yeni teknolojileri kullanmaktır. Çiftçilerin yeni teknolojileri benimsemesi kuşkusuz kısa dönemde ekonomik karlılı̆a, uzun dönemde de toplumun yaşam koşullarını iyileştirmeye ve sektörün sürdürülebilirliğine yardımcı olacaktır (Boz vd 2002; Çukur, 2016).

Sığırcılık işletmelerinde yeniliklerin düzeyi ile sosyo-ekonomik faktörler arasındaki ilişkinin tespiti üzerine Türkyılmaz ve ark. (2003), Çiçek ve ark. (2008), Yılmaz (2008), Yüksel (2009), Sezgin ve Kara (2010), Aksoy ve ark. (2011), Çukur ve Saner (2012), Boz (2014), Yang and Ju (2014) ve Gençdal ve ark. (2015) çalışmışlardır.

Erzurum ilinde süt sığırcılığı işletmelerinde verimlilik, karlılık, sürdürülebilirlik ve katma değeri artırmak adına son yıllarda sağlanan kredi destekleri ve hibeler sayesinde sektörün gelişmesine olanak sağlanmıştır. Ancak kredi destekleri ve hibeler dışında sektörün etkin ve verimli hale gelebilmesi ancak sektörde yaşanan yeniliklerin benimsenmesi ve uygulanması ile mümkün olabilecektir.

Bu çalışma, önemli bir hayvancılık potansiyeline sahip Erzurum ilinde süt sığırcılı̆ıının geliştirilmesine katkı sağlayacak politikaların oluşturulmasına katkı sağlamak amacıyla ilde faaliyet gösteren süt sığırcılığı işletmelerinde süt sağım ünitesi, süt soğutma tankı, gübre sıyırıcı, otomatik suluk, kaşıyıcı, buzağı ünitesi, karantina alanı, doğumhane, yem deposu, suni tohumlama, havalandırma, teknik destek ve silaj kullanımı gibi muhtemel yeniliklerin benimsenme düzeyinin tespit edilmesi amacıyla yapılmıştır.

\section{Materyal ve Yöntem}

Çalışma materyali, Erzurum iline süt sığırcılığı yapan Aşkale, Aziziye, Çat, Hınıs, Horasan, Karayazı, Narman, Pasinler, Şenkaya ve Yakutiye ilçelerindeki işletmelerle yüz yüze yapılan anketler oluşturmaktadır (Şekil 1). Bu işletmelere ait sığır ve işletme sayıları TUiK'ten alınmış ve Erzurum il Tarım ve Orman Müdürlüğü Veteriner Bilgi Sistemi'nden alınan sayılarla destekleniştir. 


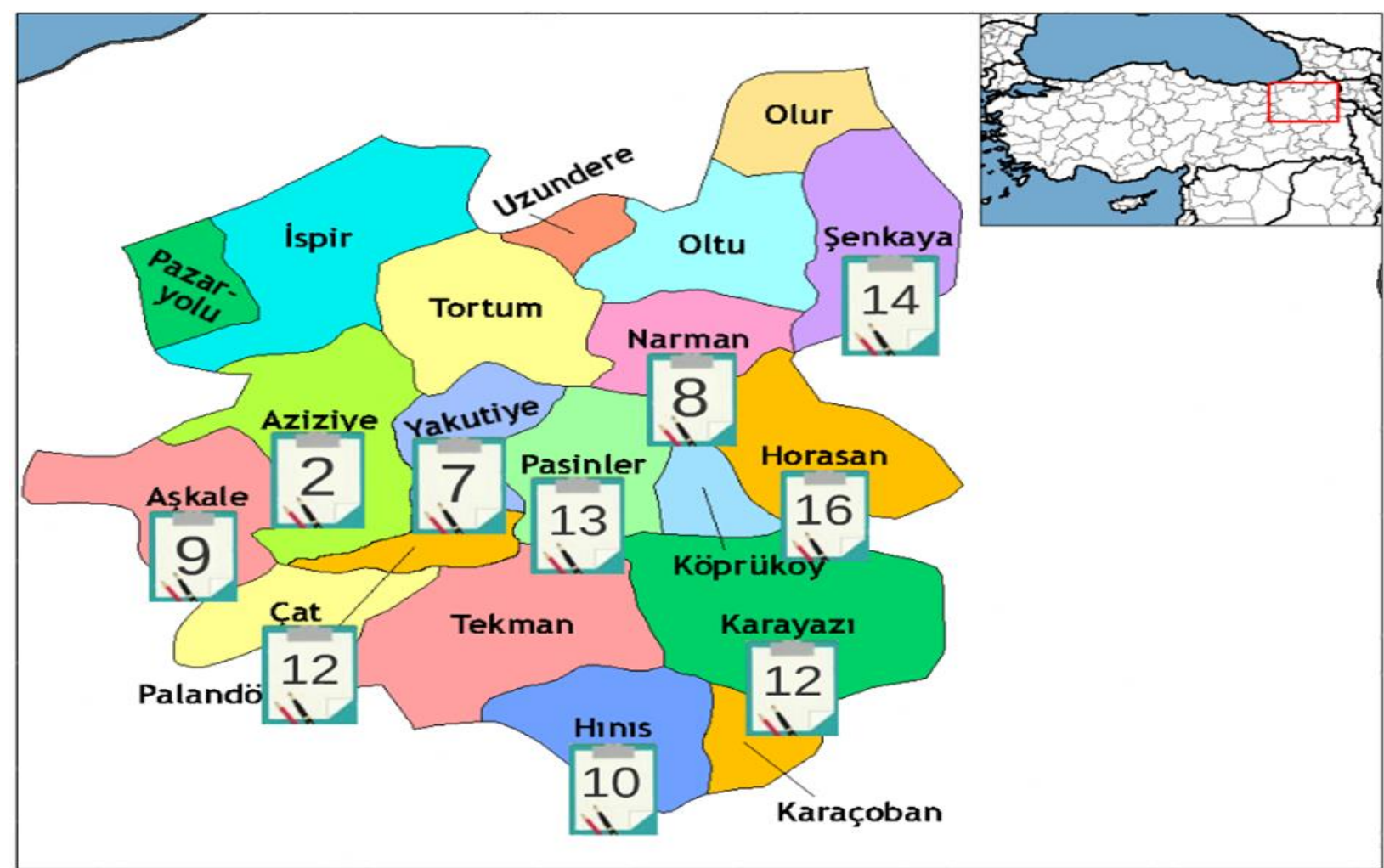

Şekil 1. Anket çalışması yapılan ilçeler ve uygulanan anket sayıları.

\section{Popülasyon ve örneklemede izlenen yöntem}

Araştırmada süt sığırcılı̆̆ı işletmelerinde uygulandığı yeniliklerin gelire olası etkilerini belirlemek amacı ile üreticiler ile yüz yüze anket çalışması yapılmıştır. Anket yapılan işletme sayısı Oransal Örnekleme Yöntemi ile tespit edilmiştir. Yöntemde yüzde 90 güven aralığı, yüzde 10 hata payı kullanılmıştır. $\mathrm{Bu}$ örnekleme kitlesinin belirlenmesinde kullanılan eşitlik aşağıda verilmiştir (Newbold, 1995; Miran, 2002).

$$
\mathrm{n}=\frac{\mathrm{N} * \mathrm{p} *(1-\mathrm{p})}{(\mathrm{N}-1) * \sigma^{2} \mathrm{p}+\mathrm{p} *(1-\mathrm{p})}
$$

Formülde :

n : Örnek büyüklüğü,

$\mathrm{N}$ : Süt sığırcılığı işletme sayısı,

$\sigma^{2} \mathrm{p} \quad$ : Varyans,

$r$ : Ortalamadan sapma (\%10),

$Z_{\alpha / 2} \quad: z$ cetvel değeri (1.96),

$\mathrm{p}$ : Süt sığırcılığı işletmelerinde yeniliklerin benimsenme oranı (0.43).

Çalışmada 100 ön anketle $p$ ve $q$ değerleri belirlenmiştir.

$$
\sigma_{p}^{2}=\left(\frac{0.10}{1.96}\right)^{2}=0.0026
$$

$$
n=\frac{30000 * 0.43 * 0.57}{(29999 * 0.0026)+(0.43 * 0.57)}=93.87
$$

Anket sayısı yüzde 10 arttırılarak 103 süt sığırcılı̆ı̆ işletmesi ile görüşüme gerçekleşmiştir. Veri değerlendirmede kullanılacak istatistiksel yöntemler araştırmanın amaçları doğrultusunda seçilmiştir. Araştırmanın amacı gerçekleştirmek için de Sıralı (Ordered Probit) Probit Modeli uygulanmıştır. Bu model aynı zamanda projenin diğer amaçları açısından da bütünleyici sonuçlar verdiği ifade edilebilir. Bu araştırmanın verilerinin etki analizinde kullanılmak üzere STATA ve LIMDEP gibi farklı yazılımlardan faydalanılmıştır.

\section{Veri analizinde izlenen yöntem}

Araştırmanın temel amacını gerçekleştirmek için ortalama standart sapma ve çapraz tablo gibi temel istatistiklerden yararlanılmıştır. Çiftçilerin uyguladığı tarımsal yeniliklerin benimsenme düzeyine etki eden faktörlerin belirlenmesi amacıyla sıralı (ordered) probit modeli kullanılmıştır.

Bağımlı değişken; 0 = Düşük, 1 = Orta ve $2=$ Yüksek şeklinde kodlandığı araştırmada bağımlı değişkeni hayvancılık işletmelerinde kullanılan yeniliklerden yararlanma düzeyi olarak düşük, orta ve 
yüksek şeklinde üç kategoriye ayrılmıştır. Süt sağım ünitesi, süt soğutma tankı, gübre sıyırıcı, otomatik suluk, kaşıyıcı, buzağı ünitesi, karantina alanı, doğumhane, yem deposu, suni tohumlama, havalandırma, teknik destek, silaj kullanımı şeklinde on üç adet yenilik ele alınmıştır. Bu yeniliklerden hiçbirini almayan ya da yalnızca birini alanlar yararlanma düzeyi düşük (0), yeniliklerin 2-5 tanesini kullananlar orta (1), 6 ve daha fazla destekten yararlananlar yüksek (2) olarak sınıflandırılmıştır.

Bağımlı değişkenin kategorik veya ordinal olduğu durumlarda sıralı logit veya sıralı probit olasılık tahmin edicileri kullanılmaktadır.

Her iki yöntemde de maksimum en çok benzerlik fonksiyonları kullanılır. Sıralı probit model normal olasılık dağılımına dayanırken, sıralı logit model standardize edilmiş lojistik olasılık dağılımından türetilir (McKelvey and Zavoina 1975; Emeç, 2002; Terin ve Çelik Ateş, 2016). Sıralı probit modelini sıralı logit modelinden ayıran özellik, hataların normal dağılmasıdır.

Bağımlı değişkenin bu şekilde sıralı nitelikte bulunuşu, sıralı probit modelinin kullanımını daha elverişli kılmaktadır. Normal bir regresyon modeli (OLS), bağımlı değişkenin üç kategorisi arasında eşit farklılıklar varsayacağından tarafı sonuçlar verebilmektedir. Bağımlı değişkenin doğal sınırlama şeklinde olması, multinominal logit modelinin kullanılması halinde de taraflı sonuçlar çıkmaktadır. $\mathrm{Bu}$ yüzden bağımlı değişkenin kesikli kategoriler halinde olması ve bu kategorilerde doğal bir sınırlama bulunması sıralı probit modelinin uygulanacak en iyi yöntem olduğunu göstermektedir (Mohamed and Abdel-Aty 2001; Boz ve ark. 2002). edilebilir.

Ordered probit modeli aşağıdaki gibi ifade

$$
\begin{gathered}
y^{*}=b x+\varepsilon \varepsilon \sim N[0,1] \\
y=0 \text { eğer } y^{*} \leq 0, \\
y=1 \text { eğer } 0<y^{*} \leq \mu_{1}, \\
y=2 \text { eğer } \mu_{1}<y^{*} \leq \mu_{2}
\end{gathered}
$$

Burada $y^{*}$ gözlenmeyen bağımlı değişken, $\mu j^{\prime}$ ler, model içinde $\beta$ ile birlikte tahmin edilen ve $y^{\prime}$ nin alacağı değerlerin alt ve üst sınırlarını oluşturan eşik değerlerini, $\varepsilon$ normal dağılım gösteren hata terimleri vektörünü ve $N[0,1]$, yeniliklerin benimsenme olasılığını gösteren ve gözlenebilen bağımlı değişkeni gösterir (Gujarati, 2005; Greene, 2008).

$$
\operatorname{Prob}(y=0)=\Phi\left(-\beta^{\prime} x\right) \text {, }
$$

$$
\operatorname{Prob}(y=1)=\Phi\left(\mu_{1}-\beta^{\prime} x\right)-\Phi\left(-\beta^{\prime} x\right) \text {, }
$$

$$
\operatorname{Prob}(y=2)=1-\Phi\left(\mu_{1}-\beta^{\prime} x\right)
$$

Tüm bu olasılıkların pozitif olması için, $\mu$ değerlerinin $0<\mu 1<\mu 2<\ldots<\mu j-1$ olması gerekir. $\Phi$ kümülatif normal dağılım fonksiyonunu göstermektedir.

\section{Bulgular ve Tartışma}

Sıralı probit modelinin mevcut hale getirilmesinde hayvan sayısı grupları ile ele alınan bütün parametreler arasında farklı model kombinasyonlarına bakılarak en uygun model elde edilmeye çalışılmıştır. Üretici anketlerinden elde edilen veri seti dikkate alınarak oluşturulan modelde kullanılan değişkenlere ait tanımlayıcı istatistikler Çizelge 1'de verilmiştir.

Araştırma alanında yeniliklerin benimsenme düzeyinin oldukça düşük olduğu (1.23) dikkati çekmektedir. Boz (2014), çalışmasında da benzert sonuçları bulmuştur. Modelde kullanılan değişkenlerden elde edilen verilere göre işletmecinin öğrenim seviyesi dikkate alındığında ortalama 3.79 olduğu tespit edilmiştir. Öğrenim gurupları içerisinde bu seviye ilkokul ve ortaokul arasına tekabül etmektedir. Ailedeki birey sayısı 5.81 olup, işletmelerin \%64'ü tarımsal amaçlı kredi kullanmaktadır. İşletmecinin yıllık tarımsal geliri esas alındığında 2.32 olarak tespit edilmiş olup, bu değer yaklaşık yıllık 40 000-60 000 TL'ye tekabül etmektedir. İşletmecinin yıllık tarım dışı geliri ise 1.98 olarak belirlenmiş ve bu değer 20 001-40 000 TL arasındaki grubu işaret etmektedir. İşletmecilerin \%86'sının sosyal güvenliğinin olduğu, \%66'sının teknik bilgiye ulaşmada resmi kaynaklardan faydalandığı belirlenmiştir. İşletmecilerin işletme faaliyetleri ile ilgili bilgi elde etme çaba sıklığının hemen hemen ayda bir kez olduğu, yine anket uygulanan üreticilerin $\% 98$ 'inin yeni bilgi ve teknolojileri öğrenmeye istekli oldukları görülmüştür. İşletmecilerin \%92'sinin yeni bilgi ve teknolojileri uygulamanın gelirde değişiklik meydana getireceğine inandıkları belirlenmiştir. İsletmecinin \%83'ünün televizyon ve radyodan tarım programlarını takip ettikleri ve $\% 72$ 'sinin ise gazete okudukları belirlenmiştir. İşletmecilerin herhangi bir yeniliği (teknik, girdi, vb.) uygulamaya karar verirken teşvik eden neden incelendiğinde yeniliğin ucuz olmasının \%29, yenilikle ilgili bilgi sahibi olma isteğinin $\% 13$, denenebilir olmasının \%18, diğer çiftçilerin uyguluyor olmasının ise \%28 oranında etkili olduğu belirlenmiştir. İşletmecilerin \%84'ü işletmede üretilen sütün mandıraya satmakta, $\% 40$ ’ının ise üretilen sütü süt soğutma tankında muhafaza ettikleri ve yazın üretilen sütü ortalama 3 saatte pazarladıkları belirlenmiştir. 
Çizelge 1. Modelde kullanılan değişkenlerin tanımlanması

\begin{tabular}{|c|c|c|c|}
\hline Değişken Adı & Açıklama & Ortalama & $\begin{array}{c}\text { Standart } \\
\text { Sapma }\end{array}$ \\
\hline & İşletmecinin Öğrenim seviyesi & & \\
\hline ES & $\begin{array}{l}\text { Okuz Yazar Değil:1, Okuryazar:2, İlkokul:3, Ortaokul:4, Lise:5, } \\
\text { Yüksekokul:6, Üniversite:7 }\end{array}$ & 3.79 & 1.31 \\
\hline ABS & Ailedeki Birey Sayısı & 5.81 & 1.77 \\
\hline TAKK & $\begin{array}{l}\text { Tarımsal Amaçlı Kredi Kullanılması Evet: 1, Hayır: } 0 \\
\text { İşletmecinin Yıllık Tarımsal Geliri }\end{array}$ & 0.64 & 0.48 \\
\hline IYTG & $\begin{array}{l}20.000 \text { ve altı:1, 20.001-40.000:2, 40.001-60.000:3, 60.001-80.000:4, } \\
80.001 \text { ve üzeri:5 } \\
\text { İşletmecinin Yıllık Tarım Dışı Geliri }\end{array}$ & 2.32 & 1.55 \\
\hline IYTDG & $\begin{array}{l}20.000 \text { ve altı:1, 20.001-40.000:2, 40.001-60.000:3, 60.001-80.000:4, } \\
80.001 \text { ve üzeri:5 }\end{array}$ & 1.98 & 1.29 \\
\hline SG & $\begin{array}{l}\text { Sosyal Güvence Durumu } \\
\text { Evet: } 1 \text {, Hayır: } 0\end{array}$ & 0.86 & 0.34 \\
\hline ITBTED & $\begin{array}{l}\text { İşletmecinin En Çok Teknik Bilgi Temin Etme Durumu } \\
\text { Resmi Bilgi Kaynakları:1, Diğer:0 }\end{array}$ & 0.66 & 0.47 \\
\hline IFIBEECSN & $\begin{array}{l}\text { İşletme Faaliyetleri İle İlgili Bilgi Elde Etme Çaba Sıklığı Hiç:1, Yılda Bir } \\
\text { Kez:2, Yılda Birkaç Kez: 3, Arya Bir Kez:4, Her Hafta:5 }\end{array}$ & 3.38 & 1.11 \\
\hline YBTOID & Yeni Bilgi ve Teknolojileri Öğrenmeye İlgi Durumu Evet: 1, Hayır: 0 & 0.98 & 0.16 \\
\hline YBTUSGBDMGD & $\begin{array}{l}\text { Yeni Bilgi ve Teknolojileri Uygulamanın Gelirde Bir Değişiklik Meydana } \\
\text { Gelme Durumu Evet: 1, Hayır: } 0\end{array}$ & 0.92 & 0.26 \\
\hline TRTPTE & $\begin{array}{l}\text { TV ve Radyodan Tarım Programlarını Takip Etme Durumu Evet: 1, } \\
\text { Hayır: } 0\end{array}$ & 0.83 & 0.38 \\
\hline GO & Gazete Okuma Durumu Evet: 1, Hayır: & 0.72 & 0.45 \\
\hline HBYUKVEUO & $\begin{array}{l}\text { Herhangi Bir Yeniliği Uygulamaya Karar Verirken En Çok Teşvik Nedeni } \\
\text { Ucuz Olması:1, Diğer:2 }\end{array}$ & 0.29 & 0.45 \\
\hline HBYUKVEBO & $\begin{array}{l}\text { Herhangi Bir Yeniliği Uygulamaya Karar Verirken En Çok Teşvik Nedeni } \\
\text { Yenilik IIle İlgili Bilgi Sahibi Olmak:1, Diğer:0 }\end{array}$ & 0.13 & 0.33 \\
\hline HBYUKVEDO & $\begin{array}{l}\text { Herhangi Bir Yeniliği Uygulamaya Karar Verirken En Çok Teşvik Nedeni, } \\
\text { Denenebilir Olması:1, Diğer:0 }\end{array}$ & 0.18 & 0.39 \\
\hline HBYUKVEDCU & $\begin{array}{l}\text { Herhangi Bir Yeniliği (teknik, girdi,vb.) Uygulamaya Karar Verirken En } \\
\text { Çok Teşvik Nedeni Diğer Çiftçilerin Uyguluyor Olması:1, Diğer:0 }\end{array}$ & 0.28 & 0.45 \\
\hline USNEP & Üretilen Sütün Pazarlanma Durumu Mandıra:1, Bakkal-Market:0 & 0.84 & 0.36 \\
\hline USNAP & Üretilen Sütün Toplanma Durumu Süt Tankı:1, Süt Bidonları:0 & 0.40 & 0.49 \\
\hline YUSHHZDP & $\begin{array}{l}\text { Yazın Üretilen Sütün Hangi Zaman Diliminde Pazarlanabilmesi Durumu } \\
1 \text { saat:1, } 3 \text { Saat:2, } 5 \text { Saat:3, } 8 \text { Saat:4 }\end{array}$ & 1.90 & 0.79 \\
\hline BBHBK & $\begin{array}{l}\text { Büyükbaş hayvan birimine göre gruplar (I Grup:0-10 adet, II Grup:11- } \\
20 \text { adet, III Grup:21-50 adet, IV Grup:51 ve üzeri adet) }\end{array}$ & 2.64 & 0.93 \\
\hline \multicolumn{4}{|l|}{$\begin{array}{l}\text { Bağımlı } \\
\text { Değişken }\end{array}$} \\
\hline YEN & Benimseme düzeyi (Düşük=0, Orta=1 ve Yüksek=2) & 1.23 & 0.70 \\
\hline
\end{tabular}

Erzurum ili süt sığırcılığı işletmelerinin yenilikleri benimsemesi açısından değerlendirilmesi amacıyla oluşturulan sıralı probit modeline ait katsayı ve birim (marjinal) etki sonuçları Çizelge 2'de verilmiştir. Yeniliklerin benimsenme düzeyinin üç gurupta ele alındığı modelde eşik değer parametresi (Mu (1) \%1 düzeyinde önemli bulunmuştur. Eşik değerlerin ekonometrik olarak önemli bulunması, yeniliklerin benimsenme düzey gruplandırmasının anlamlı olduğunu göstermektedir.

Ordered Probit Model sonuçlarına göre; ailedeki birey sayısı, tarımsal amaçlı kredi kullanım durumu, yıllık tarım dışı gelir, sosyal güvenlik, yeni teknolojileri uygulamanın gelirde değişim meydana getirmesi, yeniliğin ucuz olması, yenilikle ilgili bilgi sahibi olmak, yeniliğin denenebilir olması, yeniliği diğer çiftçilerin uyguluyor olması, sütün pazarlama 
durumu, sütün pazarlama şekli, sütün pazarlama süresi ve büyükbaş hayvan sayısı değişkenleri istatistiksel açıdan önemli bulunmuştur. Model sonucunda öğrenim durumu ile yeniliklerin benimsenmesi arasında önemli ilişki bulunamamıştır. Aynı bölgede yapılan "Analysis of the factors affecting the adoption of innovations in dairy farms in Erzurum Province, Turkey" adlı çalışmada, Erzurum iline ait İspir, Hınıs, Pasinler ve Karayazı ilçelerinde yeniliklerin benimsenmesi ile öğrenim seviyesi arasında pozitif ve önemli bir ilişki olduğu ve verimi düşük yerli ırklarla çalışmanın yeniliklerin benimsenmesinin olumsuz yönde etkilediği tespit edilmiştir (Aksoy ve ark. 2011). Marjinal etkiler ele alındığında ise ailedeki birey sayısı, tarımsal amaçlı kredi kullanım durumu, yıllık tarım dışı gelir, sosyal güvenlik, yeniliğe ilgi duyma, yeni teknolojileri uygulamanın gelirde değişim meydana getirmesi, yeniliğin ucuz olması, yenilikle ilgili bilgi sahibi olmak, yeniliğin denenebilir olması, yeniliği diğer çiftçilerin uyguluyor olması, sütün pazarlama durumu, sütün pazarlam şekli ve büyükbaş hayvan sayısı değişkenleri istatistiksel açıdan önemli bulunmuştur.

Sıralı probit model sonucunda ailedeki birey sayısının artması yeniliklerin benimseme düzeyi orta grupta olma olasılığını artırırken yeniliklerin benimsenme düzeyi yüksek olan gurupta olma olasılığını azaltmaktadır. Ailedeki birey sayısının artması kişilerin yenilikleri benimseme düzeyi orta olan grupta olma olasılığını \%99 artırırken üçüncü $(\mathrm{Y}=2)$ grupta olma olasılığını \%10 azaltmaktadır.

Tarımsal amaçlı kredi kullanımı ile üreticinin yeniliklerden faydalanma düzeyi yüksek gurupta olma olasılığı arasında zıt yönlü ilişki vardır. Oysa tarımsal kredi kullanımının artması bireyin yeniliklerden yararlanma düzeyi orta grupta olma olasılığını artırmaktadır. Bireyin tarımsal kredi kullanması ikinci grupta olma ihtimalini \%29 artırırken üçüncü grupta olma ihtimalini \%30 azaltmaktadır.

İşletmede tarım dışı gelirin varlığı daha fazla yeniliğin benimsendiği üçüncü yenilik grubunda bulunma ihtimalini artırırken, orta düzeyde yeniliğin benimsendiği ikinci grupta bulunma ihtimalini azaltmaktadır. İşletmede tarım dışı gelirin varlığı üçüncü grupta bulunma ihtimalini \%69, arttırırken, ikinci grupta bulunma ihtimalini \%68 azaltmaktadır. Bu sonuç tarım dışı gelir varlığının yenilikleri daha fazla benimseyen modern işletmelerde daha fazla olduğunu göstermektedir. Modern hayvancılığı daha çok tarım dışında ek geliri olan bireylerin yaptığını göstermektedir.

İşletmenin hayvan varlığının artması, yeniliklerin benimsenme düzeyi düşük olan gruplarda bulunma ihtimalini azaltırken, daha fazla yenilik kullanan gruplarında bulunma intimalini artırmaktadır. İşletmenin hayvan varlığının 1 BBHB artması ikinci grupta bulunma ihtimalini \%32 azaltırken, üçüncü grup işletmelerde bulunma ihtimalini \%32 artırmaktadır. Kısaca, hayvan varlığının artması, yeniliklerin benimsenme düzeyini de artırmaktadır.

\section{Sonuç ve Öneriler}

Erzurum ilinde süt sığırcılığı yapan işletmelerde yeniliklerin benimsenmesi üzerinde etkili olan faktörlerin tespit edilmesi üzerine yapılan çalışmada, üreticilerin 13 adet yeniliğin ortalama 1.23 adetini kullandığı belirlenmiştir.

Sonuç olarak, Erzurum ilinde faaliyet gösteren işletmeler için yeniliğin sağladığı katma değere ilişkin farkındalık oluşturmak, yenilikçiliği daha ulaşılabilir ve ucuz kılmaya yönelik politikaların yanı sıra işletmelerin diğer sektörlerle entegre edilmesi ve ölçek açısından daha büyük nitelikli işletmelerle ticari ilişkiye girmelerinin teşvik edilmesi önerilebilir. Bu kapsamda, zikredilen hususlara ilişkin olarak aşağıda bir dizi önlemler yer almaktadır.

Yenilikleri benimseyip kullanmanın diğer sektörlerde olduğu gibi tarım sektöründe de önemli katma değer sağladığı ve karlılığı artırıcı etkisi olduğunu hem kamu sektörü çalışanları hem de işletme sahipleri kabul etmektedir. Görerek öğrenen bir tarım toplumuna sahip Türkiye'de, önder çiftçilerin gerek yurt içi gerekse de yurt dışında yer alan iyi uygulama örneklerini görmeleri sağlanarak yeni teknolojileri benimsemelerine katkı sağlayacaktır.

Aynı şekilde öğrenim düzeyi yüksek ve diğer sektörlerde tecrübe kazanan ve tarım dışı geliri olan bireylerin sektöre dahil olması ile tarımsal gelir arasında pozitif yönde bir ilişki bulunmaktadır. Bu nedenle hayvancılık sektörüne yönelik desteklemelerde özellikle öğrenim seviyesi yüksek ve ticari tecrübesi bulunan bireylere yönelik politikalar geliştirilmelidir. 
Türk Tarım ve Doğa Bilimleri Dergisi 6(3): 424-431, 2019

Çizelge 2. Ordered probit model sonuçları

\begin{tabular}{|c|c|c|c|c|}
\hline \multirow{2}{*}{ Değişkenler } & \multirow{2}{*}{ Katsayılar } & \multicolumn{3}{|c|}{ Marjinal Etkiler } \\
\hline & & $Y=0$ & $Y=1$ & $Y=2$ \\
\hline Sabit & $\begin{array}{c}-3.35452^{* *} \\
(-1.99)\end{array}$ & -- & -- & -- \\
\hline ES & $\begin{array}{c}-0.12790 \\
(0.80)\end{array}$ & $\begin{array}{c}-0.00047 \\
(0.56)\end{array}$ & $\begin{array}{c}0.4944 \\
(0.78)\end{array}$ & $\begin{array}{c}-0.4991 \\
(-0.79)\end{array}$ \\
\hline ABS & $\begin{array}{c}-0.25747^{* *} \\
(-2.08)\end{array}$ & $\begin{array}{c}0.00095 \\
(0.70)\end{array}$ & $\begin{array}{c}0.9952^{*} \\
(1.88)\end{array}$ & $\begin{array}{c}-0.10048^{*} \\
(-1.90)\end{array}$ \\
\hline TAKK & $\begin{array}{c}-0.76735^{*} \\
(-1.92)\end{array}$ & $\begin{array}{c}0.00250 \\
(0.67)\end{array}$ & $\begin{array}{c}0.29481^{*} \\
(1.94)\end{array}$ & $\begin{array}{c}-0.29731^{*} \\
(-1.95)\end{array}$ \\
\hline IYTG & $\begin{array}{c}-0.13747 \\
(0.77)\end{array}$ & $\begin{array}{c}-0.00051 \\
(-0.60)\end{array}$ & $\begin{array}{c}-0.05314 \\
(-0.75)\end{array}$ & $\begin{array}{l}0.5365 \\
(0.75)\end{array}$ \\
\hline IYTDG & $\begin{array}{c}1.76148^{* * *} \\
(3.74)\end{array}$ & $\begin{array}{c}-0.00653 \\
(-0.75)\end{array}$ & $\begin{array}{c}-0.68088^{* * *} \\
(-2.74)\end{array}$ & $\begin{array}{c}0.68741^{* * *} \\
(2.85)\end{array}$ \\
\hline SG & $\begin{array}{c}0.97494^{*} \\
(1.80)\end{array}$ & $\begin{array}{c}-0.01261 \\
(-0.63)\end{array}$ & $\begin{array}{c}-0.31021^{*} \\
(-1.81)\end{array}$ & $\begin{array}{c}0.32282^{*} \\
(1.85)\end{array}$ \\
\hline ITBTED & $\begin{array}{c}0.11900 \\
(0.29)\end{array}$ & $\begin{array}{c}-0.00047 \\
(-0.25)\end{array}$ & $\begin{array}{c}-0.04575 \\
(-0.29)\end{array}$ & $\begin{array}{l}0.4622 \\
(0.29)\end{array}$ \\
\hline IFIBEECSN & $\begin{array}{c}0.29023 \\
(1.61)\end{array}$ & $\begin{array}{c}-0.00108 \\
(-0.65)\end{array}$ & $\begin{array}{c}-0.11218 \\
(-1.54)\end{array}$ & $\begin{array}{c}0.11326 \\
(1.55)\end{array}$ \\
\hline YBTOID & $\begin{array}{c}-1.39189 \\
(-1.30)\end{array}$ & $\begin{array}{c}0.00126 \\
(0.62)\end{array}$ & $\begin{array}{c}0.47078^{* *} \\
(2.12)\end{array}$ & $\begin{array}{c}-0.47205^{* *} \\
(-2.12)\end{array}$ \\
\hline YBTUSGBDMGD & $\begin{array}{c}1.68635^{* *} \\
(2.25)\end{array}$ & $\begin{array}{c}-0.06561 \\
(-0.78)\end{array}$ & $\begin{array}{c}-0.36416^{*} \\
(-1.70)\end{array}$ & $\begin{array}{c}0.42977^{* *} \\
(2.11)\end{array}$ \\
\hline TRTPTE & $\begin{array}{c}-0.30098 \\
(-0.73)\end{array}$ & $\begin{array}{c}0.00085 \\
(0.54)\end{array}$ & $\begin{array}{c}0.11803 \\
(0.73)\end{array}$ & $\begin{array}{c}-0.11888 \\
(-0.73)\end{array}$ \\
\hline GO & $\begin{array}{c}-0.60902 \\
(-1.38)\end{array}$ & $\begin{array}{c}0.00170 \\
(0.69)\end{array}$ & $\begin{array}{c}0.23687 \\
(1.37)\end{array}$ & $\begin{array}{c}-0.23858 \\
(-1.38)\end{array}$ \\
\hline HBYUKVEUO & $\begin{array}{c}1.74163^{* *} \\
(2.41)\end{array}$ & $\begin{array}{c}-0.00535 \\
(-0.76)\end{array}$ & $\begin{array}{c}-0.60521^{* * *} \\
(-3.48)\end{array}$ & $\begin{array}{c}0.61056^{* * *} \\
(3.48)\end{array}$ \\
\hline HBYUKVEBO & $\begin{array}{c}1.43202^{*} \\
(1.72)\end{array}$ & $\begin{array}{c}-0.00199 \\
(-0.66)\end{array}$ & $\begin{array}{c}-0.50114^{* *} \\
(-2.49)\end{array}$ & $\begin{array}{c}0.50313^{* *} \\
(2.49)\end{array}$ \\
\hline HBYUKVEDO & $\begin{array}{c}2.64261 * * * \\
\quad(3.12)\end{array}$ & $\begin{array}{c}-0.00506 \\
(-0.77)\end{array}$ & $\begin{array}{c}-0.72630^{* * *} \\
(-6.42)\end{array}$ & $\begin{array}{c}0.73136^{* * *} \\
(6.14)\end{array}$ \\
\hline HBYUKVEDCU & $\begin{array}{c}1.30548^{*} \\
(1.92)\end{array}$ & $\begin{array}{c}-0.00352 \\
(-0.71)\end{array}$ & $\begin{array}{c}-0.48136^{* *} \\
(-2.30)\end{array}$ & $\begin{array}{c}0.48489 * * \\
(2.30)\end{array}$ \\
\hline USNEP & $\begin{array}{c}-1.59974 * * * \\
(-2.79)\end{array}$ & $\begin{array}{c}0.00247 \\
(0.69)\end{array}$ & $\begin{array}{l}0.54734^{* * *} \\
\quad(4.49)\end{array}$ & $\begin{array}{c}-0.54981^{* * *} \\
(-4.46)\end{array}$ \\
\hline USNAP & $\begin{array}{c}1.41856^{* * *} \\
(2.90)\end{array}$ & $\begin{array}{c}-0.00626 \\
(-0.80)\end{array}$ & $\begin{array}{c}-0.51465^{* * *} \\
(-3.20)\end{array}$ & $\begin{array}{c}0.52091^{* * *} \\
(3.26)\end{array}$ \\
\hline YUSHHZDP & $\begin{array}{c}0.39217^{*} \\
(1.68)\end{array}$ & $\begin{array}{c}-0.00145 \\
(-0.66)\end{array}$ & $\begin{array}{c}-0.15159 \\
(-1.59)\end{array}$ & $\begin{array}{c}0.15304 \\
(1.61)\end{array}$ \\
\hline BBHBK & $\begin{array}{l}0.81581 * * * \\
\quad(2.65)\end{array}$ & $\begin{array}{c}-0.00302 \\
(-0.67) \\
\end{array}$ & $\begin{array}{c}-0.31534^{* *} \\
(-2.40)\end{array}$ & $\begin{array}{c}0.31837^{* *} \\
(2.44)\end{array}$ \\
\hline $\mathrm{Mu}(1)$ & $\begin{array}{c}3.26911^{* * *} \\
(6.40)\end{array}$ & & & \\
\hline $\begin{array}{l}\text { Logaritmik Olabi } \\
\text { KIsıtlı Logaritmik }\end{array}$ & $\begin{array}{l}\text { iyonu }-43.34255 \\
\text { Fonksiyonu }-104.50355\end{array}$ & & $\begin{array}{l}\text { Ki-Kare (20 d.f.) } 12 \\
\text { Önem Seviyesi } 0.0\end{array}$ & \\
\hline
\end{tabular}

Not: ${ }^{* * *}, * *, *==>$ Önem Seviyesi: 99\%, 95\%, 90\%. Parantez içerisindeki değerler t değerleridir.

Ölçek ekonomisi tüm sektörlerde olduğu gibi tarım sektörünün karlılı̆̆ı ve katma değerinin arttırılmasında önemli bir husustur. Ölçek büyüdükçe birim başı maliyetler düşecek ve uzmanlaşma 
dolayısıyla verimlilik artacaktır. Çalışma sonucunda da görüldüğü gibi hayvancılıktan para kazanan büyük işletmelerin yenilikleri daha kolay benimsedikleri açıkça görülmektedir. Bu doğrultuda, oldukça düşük ölçekli olan işletme büyüklüğünü artırmaya yönelik desteklemelerin verilmesi önem arz etmektedir.

¥: Bu çalışma Sinan KILIÇTEK'in Yüksek Lisans tezinden üretilmiştir.

\section{Kaynaklar}

Akbay, C., Boz, I. 2005. Turkey's livestock sector: Production, cosumption and policies. World, 79(27.64): 28-44.

Aksoy, A. Külekçi, M. ve Yavuz F. 2011. Analysis of the Factors affecting the adoption of innovations in dairy farms in Erzurum province, Turkey. African Journal of Agricultural Research, 6(13): 29662970.

Anonim, 2019. Türkiye İstatistik Kurumu İnternet Sayfası, www.tuik.gov.tr.

Boz, i. 2014. Determination of best management practices and innovations in beef cattle farming and their adoption in the Eastern Mediterranean Region of Turkey. Bulgarian Journal of Agricultural Science, 20(3): 552-562.

Boz, i. Akbay, C., Orhan, E. 2002. Mısır üretiminin Kahramanmaraş'ta Benimsenmesi ve yayılmasını etkileyen faktörler. Türkiye V. Tarım Ekonomisi Kongresi, 18-20.

Çiçek, H. Cevger, Y., Tandoğan, M. 2008. SocioEconomic factors affecting the level of adoption of innovations in dairy cattle enterprises. Ankara Üniv Vet Fak Dergisi 55: 183-187.

Çukur, F., Saner, G. 2012. Süt sığırcılığının geliştirilmesinde birliklerin rolü ve önemi: Milas ilçesi süt üreticileri birliği örneği. X. Tarım Ekonomisi Kongresi, Konya, Türkiye, 5-7.

Çukur, T. 2016. Factors affecting dairy farmers application of agricultural innovations: A Case study from Muğla province. Turkish Journal of Agriculture-Food Science and Technology, 4(7): 611-617.

Emeç, H. 2002. Ege Bölgesi Tüketim Harcamaları İçin Sıralı Logit Tahminleri ve Senaryo Sonuçları.

Gençdal, F., Terin, M., Yıldırım, İ. 2015. Süt sığırcılığı işletmelerinde suni tohumlama yaptırma durumuna etkieden faktörlerin belirlenmesi üzerine bir araştırma: Van ili Gevaş ilçesi örneği. Anadolu Tarım Bilimleri Dergisi, 30(3): 254-259.
Greene, W.H. 2008. Econometric Analysis. Sixth Edition. Pearson Prentice Hall Upper Saddle River, New Jersey, 07458.

Gujarati, D.N. 2005. Sangeetha (2007). Basic econometrics, 4: 304-331.

Kara, A., Kızıloğlu, S. 2014. Meraya Dayalı hayvancılık yapan işletmelerde optimum ürün bileşiminin belirlenmesi: Erzurum ili örneği. Atatürk Üniversitesi Ziraat Fakültesi Dergisi, 1: 63-73.

McKelvey, R.D., Zavoina, W. 1975. A statistical model for the analysis of ordinal level dependent variables. Journal of Mathematical Sociology, 4(1): 103120.

Miran, B. 2002. Temel İstatistik, Ege Üniversitesi Basımevi, İzmir, $288 \mathrm{~s}$.

Mohamed, A., Abdel-Aty, A. 2001. Using ordered probit modeling to study the effect of ATIS on transit ridership. Transportation Research Part C, 9: 265-267.

Newbold, P. 1995. Statistics for Business and Economics, Prentice-Hall International, New Jersey.

Sezgin, A., Kara, A. 2010. Analysis of the factors having effect on the size of animal husbandry farms: The case of Erzurum province. Journal of Animal and Veterinary Advances, 9(15): 2057-2060.

Terin, M., Çelik Ateş, H. 2016. Tarımda örgütlenmeye etki eden faktörlerin belirlenmesi üzerine bir çalışma: Van ili örneği. Türk Tarım ve Doğa Bilimleri Dergisi, 3(1): 38-44.

Türkyılmaz, M.K., Bardakçıoglu, H.E., Nazlıgül, A. 2003. Aydin ili süt sığırcılık işletmelerinde yeniliklerin benimsenmesine etkili olan sosyo-ekonomik faktörler. Turkish Journal of Veterinary \& Animal Sciences, 27(6): 1269-1275.

Yang, W.Y., Ju, X.F. 2014. Analysis of Farmers technology innovation adoption impacted by internal and external factor. In Management Science \& Engineering (ICMSE), 2014 International Conference on (pp. 1512-1517). IEEE.

Yılmaz, F. 2008. Osmaniye İli Düziçi İlçesinde Hayvancılık Yapan Tarım İşletmelerinde Yeniliklerin Benimsenmesi ve Yayılmasında Kooperatiflerin Rolü Yüksek Lisans Tezi Çukurova Üniversitesi Fen Bilimleri Enstitüsü, Tarım Ekonomisi Bölümü, Adana.

Yüksel, M. 2009. Köy-Koop’a Üye Olan ve Süt Sığırcılığı Yapan İşletmeler İle Üye Olmayıp Süt Sığırcılığı Yapan İşletmelerin Tarımsal Yeniliklerin Benimsenmesi Açısından Karşılaştırılması. Yüksek Lisans Tezi, Çanakkale Onsekiz Mart Üniversitesi Fen Bilimleri Enstitüsü Tarım Ekonomisi Anabilim Dalı, Çanakkale. 